\title{
Pendampingan Desa Mandiri Dalam Strategi Branding Simplisia Potensi Lokal Kemasan Produk Guna Meningkatkan Kesejahteraan Masyarakat Kecamatan Poncokusumo
}

\author{
${ }^{1 *}$ Sri Endah Indriwati, ${ }^{2}$ Eko Sri Sulasmi, ${ }^{3}$ Sri Rahayu Lestari, \\ ${ }^{4}$ Bagus Priambodo, ${ }^{5}$ Hisyam Baidlowi, ${ }^{6}$ Lutfiyanti Fanani \\ Universitas Negeri Malang; Jalan Semarang 5 Malang \\ *Corresponding author: sri.endah.fmipa@um.ac.id
}

\begin{abstract}
Abstrak
Kesejahteraan masyarakat merupakan hal penting yang perlu terus ditingkatkan, salah satunya dapat dilakukan dengan mengelola sumber daya alam atau potensi lokal. Kecamatan Poncokusumo merupakan bagian dari wilayah Taman Nasional Bromo Tengger Semeru (TNBTS) yang menyimpan berbagai potensi lokal, salah satunya yaitu tanaman berpotensi obat. Keberadaan tanaman berpotensi obat dapat dijadikan sebagai tonggak dalam meningkatkan kesejahteraan masyarakat di Kecamatan Poncokusumo, terutama di desa Argosuko. Berkaitan dengan permasalahan tersebut, dilakukan beberapa upaya pendampingan: 1) pembuatan simplisia, 2) penyusunan komposisi simplisia sebagai bahan obat, hingga 3) pengemasan dan pengurusan ijin PIRT/BPOM. Partisipan dalam penelitian dan pengabdian adalah ibu-ibu PKK desa Argosuko sebanyak 30 orang, berasal dari 3 dusun (Keden, Wangkal Kidul, dan Wangkal Lor). Hasil penelitian dan pengabdian masyarakat menunjukkan bahwa seluruh ibu-ibu PKK bisa mengikuti kegiatan pendampingan yang diadakan. Melalui program pendampingan, ibu-ibu PKK memperoleh pembekalan bagaimana memperkaya pengetahuan tentang pembuatan bermacam-macam simplisia yang memiliki nilai ekonomi tinggi, bagaimana menyusun komposisi simplisia sebagai bahan jamu herbal, bagaimana cara melakukan pengemasan yang menarik konsumen, dan bagaimana mendapatkan legalitas dari dinas terkait. Sehingga harapannya, di masa depan ibu-ibu PKK dapat mengatasi masalah perekonomian akibat ketidaktahuan dalam mengelola potensi lokal sebagai sumber ekonomi untuk meningkatkan kesejahteraan keluarga dan masyarakat.
\end{abstract}

Kata kunci-pendampingan, branding, simplisia, kesejahteraan masyarakat

\section{Abstract}

Community welfare is an important thing that needs to be improved, one of which can be done by managing natural resources or local potential. Poncokusumo Subdistrict is part of the Bromo Tengger Semeru National Park (TNBTS) which stores a variety of local potential, one of which is a potentially medicinal plant. The existence of potential medicinal plants can be used as a milestone in improving the welfare of the community in the District of Poncokusumo, especially in the village of Argosuko. In acquintance with this problem, several assistance efforts have been made: 1) manufacturing of simplicia, 2) preparation of the composition of simplicia as a medicinal ingredient, up to 3) packaging and processing of PIRT/BPOM permits. Participants in the research and service were 30 PKK Argosuko village women, coming from three hamlets (Keden, Wangkal Kidul, and Wangkal Lor). The results of research and community service show that all PKK can participate in the mentoring activities that are held. Through the mentoring program, PKK got a briefing on how to enrich their knowledge about making various kinds of simplicia that have high economic value, how to arrange the composition of simplicia as herbal medicinal ingredients, how to do packaging that attracts consumers, and how to obtain legality from related agencies. Therefore, it is expected in the future, PKK can overcome economic problems due to ignorance in managing local potential as an economic source to improve the welfare of families and communities.

Keywords - assistance, branding, simplicia, community welfare 


\section{Indriwati dkk. I Jurnal Karinov Vol. 2 No. 3 (2019) 185-190}

\section{PENDAHULUAN}

$\mathrm{K}$ esejahteraan masyarakat merupakan hal penting yang perlu terus ditingkatkan. Pembangunan kesejahteraan sosial masyarakat diatur dalam UU Nomor 11 Tahun 2009 untuk mewujudkan kehidupan yang layak dan bermartabat, serta untuk memenuhi hak atas kebutuhan dasar warga negara demi tercapainya kesejahteraan. Kesejahteraan masyarakat dapat terus ditingkatkan melalui pemberdayaan masyarakat dalam mengelola sumber daya alam ataupun potensi lokal (Teja, 2015). Kabupaten Malang memiliki potensi ekonomi yang sangat besar didukung dengan kekayaan sumber daya akam yang cukup tinggi (Supanto, 2007). Salah satu wilayah yang memiliki sumber daya lokal yang memiliki potensi tinggi dan belum dimanfaatkan oleh masyarakat sekitar adalah Kecamatan Poncokusumo Kabupaten Malang.

Kecamatan Poncokusumo merupakan salah satu kecamatan yang termasuk kawasan Taman Nasional Bromo Tengger Semeru (TNBTS) (Listiyana \& Mutiah, 2017; Supriadi, 2018). Kondisi geografis Kecamatan Poncokusumo berada pada ketinggian $2500 \mathrm{~m}$ sampai $2700 \mathrm{~m}$ dari permukaan laut, dengan suhu udara berkisar antara 30 sampai $200 \mathrm{C}$. Wilayah ini memiliki topografi yang berbukit-bukit dan suhu udara yang cenderung dingin dan sejuk. Kondisi ini sangat menunjang tumbuhnya berbagai jenis tanaman termasuk dalam hal ini tamaman obat. Rentang ketinggian wilayah yang lebar memungkinkan kawasan konservasi Taman Nasional Bromo Tengger Semeru memiliki keanekaragaman hayati yang tinggi dan karakter vegerasi yang khas (Listiyana \& Mutiah, 2017).

Hasil penelitian sebelumnya menunjukkan bahwa tanaman lokal di TNBTS Kabupaten Malang belum banyak dimanfaatkan oleh warga setempat sebagai sumberdaya hayati yang berpotensi obat (Listiyana \& Mutiah, 2017). Kecamatan Poncokusumo memiliki tanaman yang berpotensi dijadikan obat, dari kelompok Herba ada 72 Divisi yang terdiri dari 53 Famili dan 51 Ordo, dari kelompok Lignosus sebanyak 55 Divisi yang terdiri dari 32 Famili dan 32 Ordo (Indriwati, 2015; Sulasmi, Indriwati, \& Suarsini, 2016). Indikasi dari kekurangpedulian masyarakat sekitar terhadap kekayaan sumberdaya hayati di lingkungannya, ditunjukkan oleh diabaikannya beberapa tanaman yang berpotensi obat dan melimpah jumlahnya. Misalnya di desa Ngadas Kecamatan Poncokusumo, tanaman bawang prei (Allium fistulosum) dipilih yang berukuran besar untuk dijual, sementara yang berukuran kecil dibuang begitu saja. Tanaman salam (Sizygium polyanthum) melimpah di desa Wangkal Kidul Kecamatan Poncokusumo. Keberadaan tanaman obat yang melimpah jika dikelola dengan baik, niscaya bisa menjadi pendukung perekonomian masyarakat. Ekonomi masyarakat bisa lebih baik karena dari berbagai bagian tanaman bisa dimanfaatkan sebagai penyedia bahan baku obatobatan/simplisia yang memiliki nilai ekonomi tinggi untuk dipasarkan (Sulasmi et al., 2016). Salah satu hal yang harus diperhatikan dalam melakukan pemasaran adalah strategi branding.

Strategi branding diartikan sebagai manajemen suatu merek dimana terdapat kegiatan yang mengatur semua elemen yang bertujuan untuk membentuk suatu brand (Schultz \& Barnes, 1999). Gelder (2015), mendefinisikan strategi branding sebagai apa yang seharusnya dicapai suatu brand dalam kaitannya dengan sikap dan perilaku konsumen. Dalam melakukan strateginya, Gelder membagi dalam brand positioning (cara untuk mendemonstrasikan keunggulan dari suatu merek dan perbedaan dari kompetitor lain), brand identity (aspek-aspek untuk menyampaikan merek dimulai dari latar belakang, prinsip merek, tujuan dan ambisi dari merek), dan brand personality (cara menambah daya tarik merek dari luar di mata konsumen).

Realita kondisi seperti yang dipaparkan di atas, dalam faktanya tidak berjalan searah dengan harapan. Kemelimpahan yang ada belum bisa menginspirasi masyarakat untuk meningkatkan kesejahteraan (perekonomian) warga secara memadai. Hal ini karena pengetahuan masyarakat terhadap berbagai jenis tanaman obat tersebut masih rendah. Ketimpangan pengetahuan masyarakat yang rendah tentang pemanfaatan potensi lokal untuk meningkatkan kesejahteraan (perekonomian) masyarakat perlu dicarikan solusi melalui pemberdayaan bahan baku obat-obatan yang sangat berpotensi untuk di pasarkan.

Berdasar uraian di atas, maka perlu dilakukan: Pendampingan Desa Mandiri dalam Strategi Branding Simplisia Potensi Lokal Kemasan Produk Guna Meningkatkan Kesejahteraan Masyarakat Kecamatan Poncokusumo.

\section{METODE}

Pendampingan branding simplisia kepada ibuibu PKK desa Argosuko dilakukan dalam 5 tahap yaitu: tahap koordinasi, tahap pendampingan produksi simplisia, tahap pendampingan menyusun komposisi bahan, pendampingan branding dan PIRT, 
dan tahap evaluasi dan refleksi. Pengabdian pendampingan ini menggunakan metode kualitatif deskriptif. Teknik pengambilan data meliputi observasi dan dokumentasi. Teknik analisis data menggunakan analisis deskriptif. Partisipan dalam pengabdian masyarakat adalah ibu-ibu PKK desa Argosuko, kecamatan Poncokusumo, yang berasal dari dusun Keden, Wangkal Kidul, dan Wangkal Lor.

\section{HASIL DAN PEMBAHASAN}

\section{a. Tahap Koordinasi}

Tahap koordinasi dilakukan terhadap Perangkat Desa, Ibu-Ibu PKK desa Argosuko Kecamatan Poncokusumo, dan Tim pengabdian masyarakat (yang terdiri dari empat orang dosen, satu mahasiswa alumni Biologi, satu mahasiswa Biologi Angkatan 2015). Koordinasi dimaksudkan untuk menyamakan persepsi tentang langkah-langkah atau metode kegiatan yang akan dilaksanakan, tujuan yang akan dicapai, lama waktu kegiatan dan jadwal pelaksanaan masing-masing tahapan yang telah direncanakan, target kelompok yang dilibatkan, dan keluaran yang akan dihasilkan.

Hasil yang disepakati pada kegiatan koordinasi dipaparkan sebagai berikut.

1. Perangkat Desa, yang terdiri dari Kepala Desa, Sekretaris Desa, Pamong Desa, dan perwakilan Ibu-Ibu PKK dari setiap dusun dengan senang hati menerima program kerjasama yang dilakukan oleh tim pengabdian masyarakat dari Universiyas Negeri Malang. Alasan diterimanya program kerjasama ini karena kegiatan pendampingan yang akan dilakukan sejalan dengan program pengabdian yang dilakukan sebelumnya yaitu tentang pemberdayaan masyarakat miskin melalui pemanfaatan potensi lokal.

2. Langkah-langkah kegiatan yang akan dilaksanakan, disepakati dilakukan melalui metode pendampingan dari berbagai nara sumber. Pendampingan produk simplisia dilakukan oleh Tim dari Universitas Negeri Malang; pendampingan penyusunan komposisi bahan simplisia dilakukan oleh Balai Materia Medica Batu; pendampingan strategi branding dan perijinan PIRT dilakukan oleh Dinas Perindustrian dan Perdagangan Kabupaten Malang.

3. Tujuan yang akan dicapai adalah memberikan solusi atas permasalahan yang dihadapi masyarakat dalam hal memperluas pengetahuan pembuatan simplisia potensi lokal berprospek ekonomi.

4. Lama waktu kegiatan, ditetapkan pada rentang waktu bulan Juli hingga Oktober 2019, dengan menyesuaikan kepadatan kegiatan ibu-ibu di desa Argosuko. Jadwal pelaksanaan masingmasing tahapan pendampingan dilakukan pada setiap hari Saptu/Minggu, dengan rentang waktu pelaksanaan antara 2 hingga 4 minggu sekali, dilakukan mulai pukul 12.00 sampai dengan pukul 17.00, bertempat di balai desa Argosuko atau di rumah warga bila satu dan lain hal balai desa sedang terpakai oleh kegiatan yang lain.

5. Dalam upaya menjaga kesinambungan program kerjasama yang telah membuahkan hasil sebelumnya, maka Ibu-Ibu PKK yang dilibatkan pada program pendampingan pada dasarnya yang pernah terlibat pada kegiatan sebelumnya. Hasil koordinasi disepakati ibu-ibu yang terlibat pada kegiatan pendampingan dibatasi sebanyak 30 orang yang berasal dari 3 dusun (Keden, Wangkal Lor, dan Wangkal Kidul).

6. Keluaran yang dihasilkan, disepakati bahwa pada akhir kegiatan pendampingan, diharapkan paling tidak ada kelompok ibu-ibu PKK yang mencapai pada tahap pemilihan 'brand' dan bisa mengajukan perijinan.

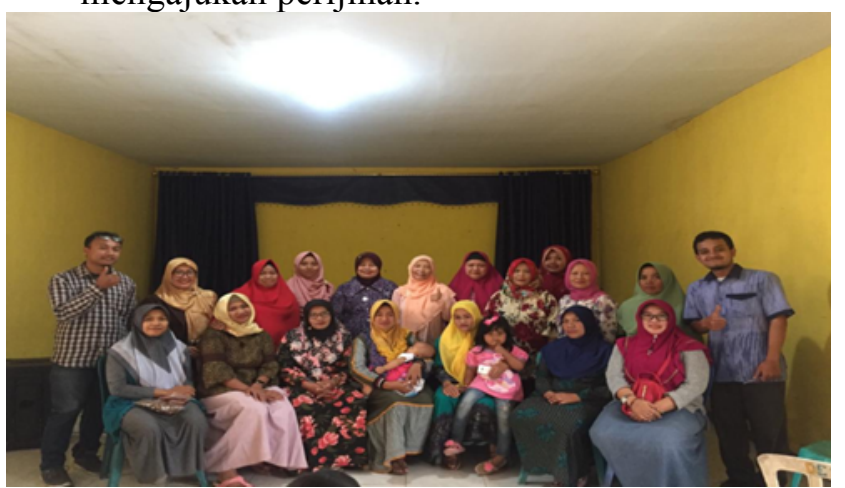

Gambar 1. Kegiatan saat Koordinasi bersama Ibu-Ibu PKK, bertempat di balai Desa Argosuko

\section{b. Tahap Pendampingan Produksi Beranekaragaman Simplisia}

Tahap ini dilakukan dalam upaya untuk memberikan pengayaan dan pemantapan materi tentang cara memproduksi beranekaragam simplisia dan bentuk simplisia potensi lokal.

Hasil pendampingan terhadap ibu-ibu PKK desa Argosuko, yang terdiri dari kelompok ibu-ibu PKK desa Keden, Wangkal kidul, dan Wangkal Lor dipaparkan sebagai berikut

1. Pengetahuan ibu-ibu PKK terhadap produk beranekaragam simplisia potensi lokal meningkat dari $35 \%$ menjadi $94,5 \%$. Hal ini 
dapat dijelaskan karena sebelum pendampingan, pengetahuan ibu-ibu PKK masih terbatas pada simplisia daun saja. Berdasar informasi yang dikumpulkan, ibu-ibu PKK tidak pernah memperoleh tambahan bekal pembuatan simplisia potensi lokal seperti yang pernah dibelajarkan oleh Tim dari Universitas Negeri Malang pada tahun sebelumnya. Hal ini berakibat bahwa pengetahuan tentang produk simplisia yang dimiliki oleh ibu-ibu PKK belum berkembang sesuai harapan. Setelah dilakukan pendampingan, pengetahuan terhadap anekaragam produk simplisia, dari yang semula hanya mengetahui simplisia daun berkembang menjadi simplisia batang, akar, bunga, dan biji.

2. Pengetahuan ibu-ibu PKK terhadap bentukbentuk simplisia meningkat dari $27 \%$ menjadi 97\%. Pada awalnya yang diketahui oleh ibu-ibu PKK hanya simplisia bentuk kering, namun melalui pendampingan pengetahuan mereka bertambah, menjadi paham terhadap bentuk produk simplisia lainnya seperti bentuk simplisia basah, gebing, dan serbuk. Hal ini terbukti ketika pendampingan, mereka menunjukkan produk simplisia yang dihasilkan.

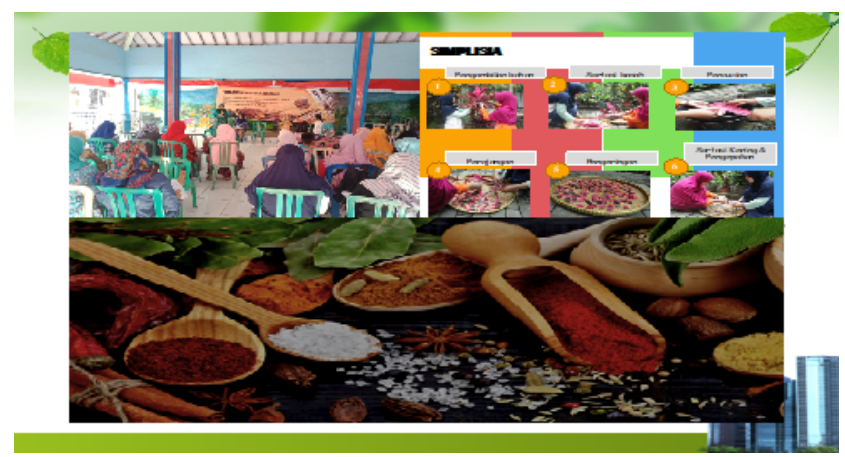

Gambar 2. Pendampingan Produksi Beranekaragam Simplisia

\section{c. Tahap Pendampingan dari Dinas Materia Medika Batu}

Tahap ini dilakukan dalam rangka membelajarkan kepada ibu-ibu PKK tentang cara mengemas, menyusun komposisi bahan jamu herbal, dan menyertakan komposisi bahan pada label kemasan. Pendampingan dilakukan oleh Balai Materia Medika Batu dan Tim dari Universitas Negeri Malang

1. Dalam hal pengemasan produk simplisia, pengetahuan ibu-ibu PKK meningkat sebesar $30 \%$, yaitu dari $70 \%$ menjadi $100 \%$. Angka peningkatan ini relatif lebih rendah dibanding dengan peningkatan pada aspek lain. Hal ini dapat dimengerti, karena masalah pengemasan sudah banyak diketahui oleh masyarakat luas melalui berbagai produk makanan yang dikonsumsi sehari-hari, seperti produk kemasan berbagai macam keripik, dan berbagai macam makanan olahan yang dikemas dalam botol.

2. Pengetahuan penyusunan komposisi bahan jamu herbal meningkat dari $23 \%$ menjadi $87 \%$. Pada awal sebelum pendampingan, pengetahuan ibuibu PKK terhadap komposisi bahan jamu herbal masih rendah. Hal ini dapat terjadi karena latar belakang pendidikan masyarakat Argosuko yang rendah (Indriwati, 2015), berdampak pada pengetahuan yang dimilikinya. Dalam memanfaatkan bahan-bahan jamu herbal, masyarakat biasanya mengandalkan rumus turunan sederhana dari nenek moyangnya, yang secara ilmiah belum pernah diuji efek sampingnya.

3. Pengetahuan ibu-ibu PKK tentang penulisan komposisi pada label kemasan meningkat dari $57 \%$ menjadi $97 \%$. Hal ini dapat dijelaskan, bahwa sebelum pendampingan ibu-ibu PKK tidak berani menulis komposisi pada produk kemasan, karena sejujurnya mereka 'takut' dan 'khawatir' menyertakan komposisi pada kemasan yang belum pernah diuji kebenarannya, kecuali pada produk serbuk Temulawak Instan yang dihasilkan. Hasil pendampingan oleh Dinas Materia Medika, disarankan bahwa komposisi dan cara penggunaan tersebut perlu ditulis pada label yang ditempelkan pada setiap kemasan produk simplisia.

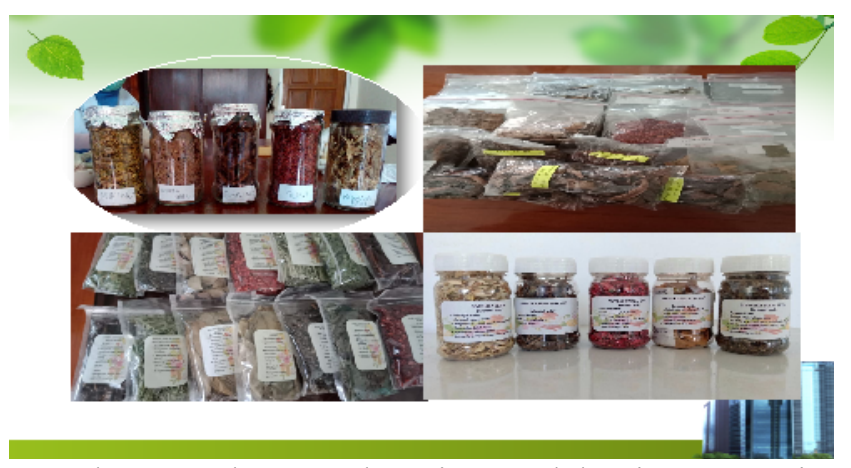

Gambar 3. Tahap Pendampingan oleh Dinas Materia Medika Batu

\section{d. Pendampingan Branding dan PIRT oleh Dinas Disperindag Kabupaten Malang}

Pendampingan branding (merk dagang) dimaksudkan agar produksi simplisia mempunyai nilai jual tinggi di mata pembelinya. Sedangkan PIRT dimaksudkan agar produk yang dihasilkan memiliki 
legalitas produksi. Hasil pendampingan menunjukkan angka yang sangat rendah, yaitu dari $0 \%$ menjadi $6 \%$. Berkaitan dengan angka yang rendah ini dapat dijelaskan bahwa

1. Partisipan yang hadir pada kegiatan pendampingan tidak konsisten dengan kesepakatan saat koordinasi dilakukan, yaitu orangnya banyak yang berbeda dengan yang pernah mengikuti pelatihan pada tahun sebelumnya, sehingga bagi yang baru mengikuti pendampingan pada tahun 2019 ini belum memiliki produk simplisia yang bisa diandalkan kualitas dan kuantitasnya untuk dicarikan 'branding' dan legalitas perijinan,

2. Produk simplisia yang dihasilkan oleh ibu-ibu PKK pada saat pendampingan, masih sangat terbatas, baik dalam hal kuantitas maupun kualitas,

3. Produk yang berhasil didampingi dalam strategi branding dan PIRT adalah produk simplisia serbuk Temulawak Instan dan Minuman sari buah (Jambu, Apel, Salak, Blimbing dan Sirsak), yang lain sedang berproses menuju branding dan PIRT/BPOM.

Strategi branding diartikan sebagai manajemen suatu merek dimana terdapat kegiatan yang mengatur semua elemen yang bertujuan untuk membentuk suatu brand (Boone \& Kurtz, 2005). Dalam melakukan strategi branding, Gelder membagi dalam brand positioning (cara untuk mendemonstrasikan keunggulan dari suatu merek dan perbedaan dari kompetitor lain), brand identity (aspek-aspek untuk menyampaikan merek dimulai dari latar belakang, prinsip merek, tujuan dan ambisi dari merek), dan brand personality (cara menambah daya tarik merek dari luar di mata konsumen) (Gelder, 2015).

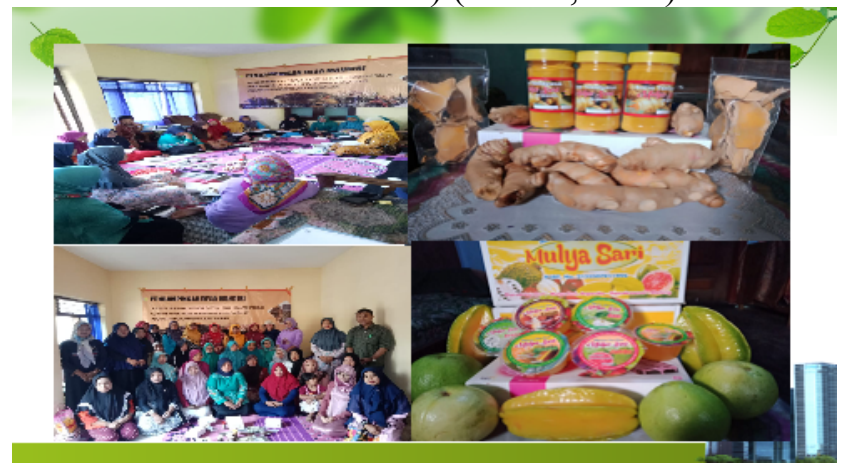

Gambar 4. Tahap Pendampingan oleh Disperindag Kabupaten Malang

\section{e. Pendampingan Branding dan PIRT oleh Dinas Disperindag Kabupaten Malang}

Pada akhir dari seluruh kegiatan pendampingan, dilakukanlah evaluasi dan refleksi hasil pendampingan. Tujuan dari kegiatan evaluasi dan refleksi adalah agar apa yang sudah dicapai maupun yang belum bisa dicapai dapat tergambarkan dan terlaporkan secara jelas. Dalam hal yang sudah dicapai, diharapkan dapat diteruskan oleh ibu-ibu PKK sebagai usaha meningkatkan perekonomian masyarakat Argosuko. Sedangkan yang belum tercapai, diharapkan dapat dicarikan solusi atas ketidak berhasilan dari apa yang sudah dilakukan.

Hasil evaluasi dan refleksi terhadap kegiatan pendampingan menunjukkan bahwa

1. Seratus persen $(100 \%)$ peserta menyatakan 'Kegiatan pendampingan sangat bermanfaat' bagi ibu-ibu PKK dalam memberikan solusi atas permasalahan yang dihadapi masyarakat dalam mengembangkan pengetahuan dan keterampilan memproduksi simplisia potensi lokal berprospek ekonomi,

2. Seratus persen $(90 \%)$ peserta menyatakan 'Kegiatan pendampingan sangat bermanfaat' bagi ibu-ibu PKK dalam memajukan desa Argosuko, khususnya di bidang kesejahteraan,

3. Seratus persen $(100 \%)$ peserta menyatakan setuju dengan keberlanjutan program ini. Bu Ary sebagai pamong desa menyanggupi siap membantu memonitor secara intens kegiatan produksi simplisia potensi lokal berprospek ekonomi bagi ibu-ibu PKK yang belum menunjukkan usaha branding dan perijinannya.

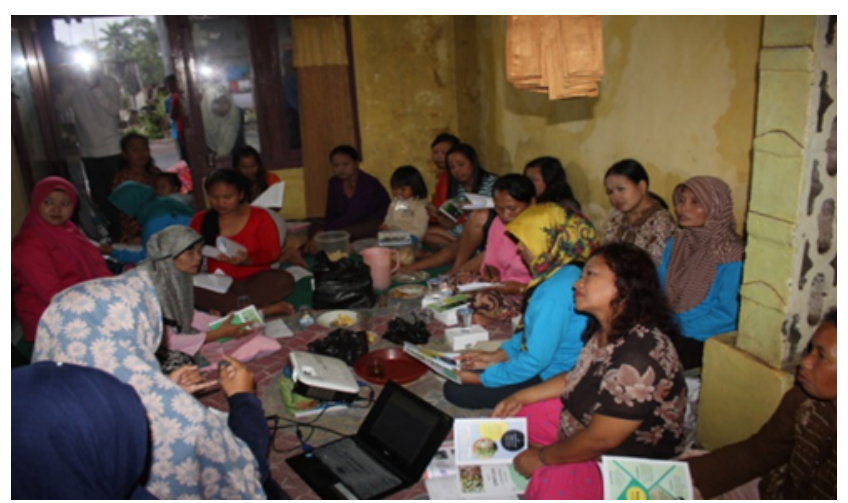

Gambar 6. Tahap Evaluasi dan Refleksi

\section{SIMPULAN}

Berdasarkan hasil kegiatan pengabdian yang telah berlangsung selama enam kali pertemuan, dapat disimpulkan bahwa pendampingan berjalan dengan lancar walaupun ada sedikit kendala diantaranya kurangnya komitmen dari para peserta. Selain itu, diyakini bahwa pendampingan yang dilakukan oleh tim pengabdian dari Universitas Negeri Malang dapat meningkatkan ibu-ibu PKK desa Argosuko kecamatan Poncokusumo dalam hal: (1) Produksi Page | 189 
macam dan kuantitas simplisia yang dihasilkan, (2) Kemampuan dalam menyusun komposisi bahan jamu, (3) Pengemasan yang 'menarik dan menjual', (4) Mengurus perijinan untuk legalitas produk. Guna menghindari kemunduran semangat dan kemalasan ibu-ibu PKK dalam memproduksi beranekaragam simplisia berkualitas dan berprospek ekonomi, diperlukan komitmen dari para peserta yang terlibat pendampingan, pemeruntah daerah, dan mitra dari Perguruan Tinggi.

\section{UCAPAN TERIMA KASIH}

Penulis menyampaikan ucapan terima kasih kepada Lembaga Penelitian dan Pengabdian kepada Masyarakat Universitas Negeri Malang melalui dana PNPB 2018” dengan nomor: 20.3.292 / UN32.14.1 / $\mathrm{PM} / 2019$.

\section{DAFTAR RUJUKAN}

Boone, L. E., \& Kurtz, D. I. (2005). Contemporary Marketing. USA: Thomson South-Western.

Gelder. (2015). Global Brand Strategy. London: Kogan Page.

Indriwati, S. E. (2015). Keanekaragaman Tanaman Obat di Kawasan Taman Nasional Bromo Tengger Semeru. Malang: UM Press.

Listiyana, A., \& Mutiah, R. (2017). Pemberdayaan Masyarakat Suku Tengger Ngadas Poncokusumo Malang dalam Mengembangkan Potensi Tumbuhan Obat dan hasil Pertanian Berbasis Etnofarmasi: Menuju Terciptanya Desa Mandiri. Journal of Islamic Medicine, 1(1), 1-8.

Schultz, D. C., \& Barnes, B. E. (1999). Strategic brand communication campaigns. USA: NTC Business Books.

Sulasmi, E. S., Indriwati, S. E., \& Suarsini, E. (2016). Preparation of Various Type of Medicinal Plants Simplicia as Material of Jamu Herbal. International Conference on Education, 1014-2024.

Supanto, F. (2007). Model Pembangunan Ekonomi Desa Berbasis Agro Ekowisata sebagai Penyangga Ekonomi Kawasan Taman Nasional Bromo Tengger Semeru: Studi pada Desa Ngadas Kecamatan Poncokusumo Kabupaten Malang. In Prosiding Seminar Nasional (pp. 506-523).

Supriadi, B. (2018). Pengembangan Ekowisata Poncokusumo melalui Grand Strategy Matrix Analysis. Jurnal Pariwisata Ponsokusumo, 3(2), 119-133. https://doi.org/10.26905/jpp.v3i2.2436
Teja, M. (2015). Pembangunan Untuk Kesejahteraan Masyrakat di Kawasan Pesisir. Jurnal Aspirasi, 6(1), 63-76. 